\title{
Exploration of beautiful village renovation against the backdrop of global tourism
}

\author{
Zhinan $\mathrm{Gao}^{1,2}$, Xusheng $\mathrm{Li}^{1,2}$, and Yangtianyi $\mathrm{Hu}^{1 *}$ \\ ${ }^{1}$ School of Civil Engineering, Longdong University, Qingyang, Gansu province, 745000, China \\ ${ }^{2}$ Provincial Key Laboratory of Engineering Properties and Application of Loess, Longdong University, Qingyang, Gansu province, \\ 745000, China
}

\begin{abstract}
With the rise of global tourism, construction of villages is facing changes in development goals and priorities. Facing the tasks of physical environment improvement and function improvement, a multidimensional beautiful village renovation system of functions, architecture, environment, and facilities is constructed. Taking the Qixi group of Jiangkou village, Zhangfang Town, Liuyang City as an example, based on the basic characteristics of natural resource, historical and cultural traditions, etc., it has promoted the overall improvement of village functions from four aspects: overall functional layout, building renovation, road renovation, and landscape. The purpose is to explore an effective way to renovate beautiful villages under the background of global tourism, and provide some practical guidance for the future renovation of beautiful villages.
\end{abstract}

\section{Introduction}

The 19th National Party Congress sounded the clarion call for rural rejuvenation. How to realize "village rejuvenation" and make the beautiful blueprint a reality and a benefit are the major issue for rural development. With the rapid development of society and economy, people's tourism ways have undergone tremendous changes, and the tourism model has shifted to a global, composite, and intelligent development model [1]. In 2016, the National Tourism Administration successively announced the national global tourism demonstration zone and the establishment unit of the demonstration zone, which laid the important role of global tourism and also showed that "global tourism" has become a national strategy [2]. Guiding the renewal of new towns and the construction of beautiful countryside with tourism will become an important strategy for the new path of urbanization with Chinese characteristics. It is another significant upgrade on the basis of China's past comprehensive "beautiful countryside" strategy, and it will "strengthen" the vast countryside of China in the coming period, so as to further lay a solid social, economic, cultural and ecological foundation for the realization of a beautiful China. However, due to the large debts in the construction of some villages in China, poor village environment quality and insufficient resource exploitation, it is not conducive to the "tourism $+"$ function, nor is it conducive to the optimal allocation of economic and social development resources and the full play of the role of tourism. This paper analyzes the content and methods of beautiful village renovation in the context of global tourism from the perspective of planners, and aims to provide more reasonable ideas for future village renovation. Based on the renovation example of Qixi group of Jiangkou Village, Zhangfang Town, Liuyang City, a practical approach to village renovation under the background of global tourism is explored.

\section{Renovation of beautiful villages in the context of global tourism}

The "village" or "old village" is centered on the family shrine, and the villages are built in turn, forming a large community of connected houses [3], that is the village. Renovation of beautiful villages is a kind of village renovation under cultural heritage and exhibition. Through the overall arrangement and design of the various elements of the village, it aims to improve and enhance the village's appearance, revitalize its vitality, and promote the comprehensive planning for the sustainable and coordinated development and construction of the economic, social, cultural and ecological environment of the village [4].

In the study of village remediation, foreign countries already have rich theoretical and practical experience, but domestic is still in the exploratory stage (as shown in Table 1). 
Table 1. Summary of theory and practice of village renovation construction at home and abroad.

\begin{tabular}{ccl}
\hline \multicolumn{2}{c}{ Classifications } & \multicolumn{1}{c}{ Contents } \\
\hline Theory $\quad$ Foreign & $\begin{array}{l}\text { Historical context, culture; residents 'living atmosphere, spiritual demands, } \\
\text { lifestyle; residents' aesthetic need; economic development. } \\
\text { Historical culture, social customs, local customs and practices, operas, legends, } \\
\text { architectural styles, human-land relations, natural environment, etc. } \\
\text { Beautify the space environment landscape; continue the historical context, consider } \\
\text { the spiritual demands of citizens; preserve rural memories, fully consider the } \\
\text { lifestyle and atmosphere of the residents. } \\
\text { Practice }\end{array}$ \\
Pay attention to spacial image planning and build a special characteristic brand.
\end{tabular}

The renovation of beautiful villages in the context of global tourism is dedicated to the visible "urban and rural beauty" and the invisible "inner beauty", so there are many differences from the settlement of villages in village planning (as shown in Table 2). Through comprehensive comparative analysis, it is suggested that the following four aspects should be done to improve beautiful villages in the context of global tourism.

Table 2. Comparison of renovation of residential areas (beautiful villages) under different backgrounds.

\begin{tabular}{|c|c|c|}
\hline & Renovation of settlements in village planning & $\begin{array}{c}\text { The renovation of beautiful village under the } \\
\text { background of global tourism }\end{array}$ \\
\hline Classifications & $\begin{array}{c}\text { Central Village; Basic Village; Characteristic } \\
\text { village. }\end{array}$ & $\begin{array}{l}\text { Points (Attractions) ; Lines ( Tourist } \\
\text { routes); Planes (Regions). }\end{array}$ \\
\hline Contents & $\begin{array}{c}\text { Layout of Residential Area; } \\
\text { Industrial Planning; } \\
\text { Road Traffic Improvement; } \\
\text { Building Renovation; } \\
\text { Infrastructure Renovation; } \\
\text { Renovation of Public Service Facilities; } \\
\text { Environmental and Heritage Conservation } \\
\text { Planning. }\end{array}$ & $\begin{array}{l}\text { Overall function layout; } \\
\text { Renovation of building style; } \\
\text { Environmental Remediation; } \\
\text { Infrastructure supporting. }\end{array}$ \\
\hline $\begin{array}{l}\text { Direction of } \\
\text { development }\end{array}$ & Building New Socialist Countryside. & Constructing a New Rural Tourism Model \\
\hline
\end{tabular}

\subsection{Overall function layout}

The overall functional layout has a leading position in the renovation of beautiful villages. The overall functional layout in the context of global tourism focuses on conforming to regional tourism planning and analyzing local tourism resources for full development. Integrate tourism resources within the framework of global tourism, and develop tourism resources from three different levels: "points, lines, and planes" (as shown in Table 3).

Table 3. Contents of different development levels.

\begin{tabular}{cc} 
Level & Content \\
\hline Points & Landscape Nodes. \\
Lines & A walking trail to connect various \\
& settlements and attractions. \\
Planes & Tourist Attractions. \\
\hline
\end{tabular}

\subsection{Renovation of building style}

The architectural style and shape improvement under the background of global tourism has a stronger tourism significance. We need to guide new construction styles to form a coexistence of new and old buildings, with similar architectural forms, uniform styles, and echoing each other. In accordance with the actual situation and regional characteristics of each element of the village architectural style, specific measures for control and improvement are formulated.

\subsection{Environmental Remediation}

A beautiful environment can be a icing on the cake for beautiful villages under the background of tourism. The rectification idea is: analyzing the environmental appearance of the area, looking for changes in the unity, deeply exploring the characteristics of the area, highlighting the characteristic landscape in the unified regional style, and creating distinctive attractions. In the improvement of specific environmental features, it can be considered from these aspects of greening and water system (as shown in Table 4). 
Table 4. Contents of environmental renovation.

\begin{tabular}{|c|c|}
\hline Classifications & Contents \\
\hline Public Greening & To plant native trees according to the terrain and use tree belts to link other greening. \\
\hline Courtyard Greening & $\begin{array}{l}\text { Respect the public opinion, and appropriately guide the villagers to choose the } \\
\text { appropriate ornamental flowers or cash crops. }\end{array}$ \\
\hline Field Greening & $\begin{array}{l}\text { The crop bloom and bear fruit in a certain period of time. Villagers are guided to } \\
\text { cultivate at the same time so that the greening of the field is always in a certain color in } \\
\text { a large area, which is forming a beautiful greening style of the field. }\end{array}$ \\
\hline River System & To develop and protect water system landscapes according to local conditions. \\
\hline
\end{tabular}

\subsection{Infrastructure supporting}

The infrastructure construction under the background of global tourism should not only satisfy the normal production and living of villagers, but also increase various types of facilities suitable for tourism development (as shown in Table 5). As an vital venation of the village, roads are the ties between various space places and functional areas. The renovation should fully pay attention to its life service and landscape organization.

Table 5. Contents of Infrastructure improvement.

\begin{tabular}{ll}
\hline \multicolumn{2}{c}{ Classifications } \\
Public Service Facilities \\
Municipal infrastructure & $\begin{array}{l}\text { To add tourism-related service facilities while meeting the basic } \\
\text { production and living conditions of villagers. } \\
\text { To anticipate future tourism development and design flexible municipal } \\
\text { infrastructure. } \\
\text { To cover all villagers and improve the convenience of villagers' life and } \\
\text { travel. } \\
\text { To connect with the main nodes so that meet the combination between } \\
\text { the conditions of production and living and the beautiful house spatial } \\
\text { landscape system. }\end{array}$ \\
\hline Trial
\end{tabular}

\section{Exploration of Qixi group of Jiangkou village, Zhangfang town, Liuyang city}

\subsection{Village Group Overview}

Jiangkou village is located in the south of Zhangfang town, Liuyang city, Hunan province, which is $4 \mathrm{~km}$ away from the Dawei mountain-Liuyang expressway exit, the South Gate of Dawei mountain and the Zhangjiafang passenger station of the Menghua Railway, $50 \mathrm{~km}$ from Liuyang, and about $120 \mathrm{~km}$ from Changsha. Provincial Highway 309, Dawei mountain-Liuyang expressway and the planned Yueyang-Ji'an railway passing from the periphery of the village; county roads (ZhangfangXiaohe Highway, Hongsheng Highway), and rural roads (Fujiang Highway) pass through the village, and the transportation location has obvious advantage.

The Qixi group is located in east of the middle of Jiangkou Village (as shown in Figure 1), with 383 persons in 87 households. The Qixi group has a long history and prosperous business in the ancient times. In its heyday, there were more than 100 shops. Today there are still some streets with some ancient street charm. The group area is rich in natural landscape resources and cultural and historical landscape resources, including naturally formed beautiful Jiziwan river sections; the reputation of "Zhangfang Fishing Village"; the Chen's Ancestral Hall, one of the seven scenic spots; and the Chen Wuxing Ancestral Hall with unique architectural style; Qixi Village with the charm of ancient streets and alleys; the place where Mao Zedong turned the danger into safeness, which has great tourism development value. The Qixi group has a flat terrain with basic farmland on the east, west, and south sides, with mountains on the north side and Xiaoxi river on the south side, where ecological environment is superior. There are dense settlements in the middle, and with the construction scale of settlements as the boundary, it's a total area of about 9.7 ha. 


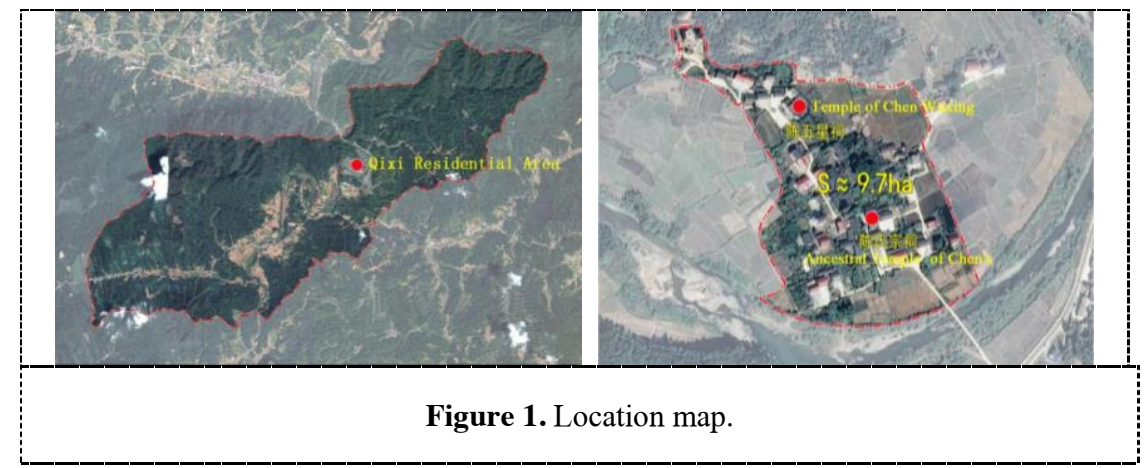

\subsection{Construction actuality}

3.2.1. Building actuality. There are three types of building structures in this group: the brick and concrete, the brick and the clay and wood structure. Among them, the number of brick houses and clay and wood structure houses is equal, and the overall building quality is average; the Hakka features of clay and wood structure buildings are more prominent. The current buildings are mostly one and two floors, with more buildings has one floor and fewer has the third floor.

3.2.2. Road actuality. The roads in the group are mainly village roads, group roads, and home roads. The village roads and group roads are all cement roads. The roads to the homes are gravel roads, and a few roads has not been hardened. The village road is about $5 \mathrm{~m}$ wide and the group road is about $3 \sim 4 \mathrm{~m}$ wide. The entrance road is about $2 \mathrm{~m}$ wide, which is inconvenient for traffic.

The beautiful natural environment and rich cultural landscape of the Qixi group gradually drowned in the long river of history. Wonderful style ancient buildings are not sufficiently protected, lack of maintenance and repair, resulting in dilapidated conditions; lack of a complete transportation and identification system, resulting in fragmented spatial structures, and broken textures; tourism resources have not been well excavated, and there is a lack of connection between scenic spots; the cultural and sports facilities are scattered, utilization is low, and public activities are scarce.

\subsection{Remediation design}

The green water and green mountains paint the thick background of the Qixi group, the original rural features, convenient transportation advantages, and good policy support, which bring more possibilities for the transformation of beautiful villages. In the context of global tourism, the Qixi Group should rely on its own resource characteristics and environmental advantages to continue to deeply rectify the village environment, vigorously implement the global tourism strategy, and take the responsibility of demonstrating the culture of the Hakka ancestral temple, inheriting the spirit of the Red Revolution, and serving villagers in Jiangkou, focus on creating tourist attractions with distinctive themes (Centennial Chen family, Hakka heritage, Red journey), promote the scenic spots of the village, strive to convert ecological resources into development advantages, turn the beautiful environment into a beautiful economy, and inject a strong impetus into the rural regeneration in the new era.

3.3.1. General graphic design. The renovation of the beautiful village takes the Chen's temple and the Chen Wuxing temple as the key objects, and the Hakka culture is the main melody. In the north-south direction, it starts from the Five star flower sea and Mao Zedong 's small Lucky square, extends to the surrounding area through the village road network and the walking path, passes through Chen ancestral temple, beautiful Bamboo garden, Qixi garden, culture and fitness square, and ends at the Chen Wuxing temple; in the east-west direction, it forms a riverside recreational landscape belt along the Xiaoxi River (as shown in Figure 2).

\begin{tabular}{|c|c|c|}
\hline & \\
\hline &
\end{tabular}


3.3.2. Building renovation guidance. Based on the principles of maintaining the original appearance of the village, keeping track of the ancestors' life, and adapting to social development, and according to the structure and appearance of the existing buildings in the group, it is divided into three categories of good quality, average quality and poor quality, using the methods of maintaining the original appearance, renovation and demolition respectively (as shown in Figure 3) to implement renovation (as shown in Table 6).

Table 6. Building renovation guidelines.

\begin{tabular}{|c|c|c|c|}
\hline $\begin{array}{l}\text { Rectification } \\
\text { Classification }\end{array}$ & Present Condition & Rectification Measures & Effect of Intension \\
\hline $\begin{array}{l}\text { Maintaining the } \\
\text { original } \\
\text { appearance }\end{array}$ & $\begin{array}{l}\text { The age is newer, the appearance } \\
\text { is better, and the surrounding } \\
\text { environment and style are poor. }\end{array}$ & $\begin{array}{l}\text { To clean, sweep and remove } \\
\text { excess debris from the } \\
\text { building facade. }\end{array}$ & \\
\hline $\begin{array}{l}\text { Regulating } \\
\text { Structure }\end{array}$ & $\begin{array}{l}\text { It is lacking in quality, function } \\
\text { and appearance, but it is necessary } \\
\text { to keep or continue to use it. }\end{array}$ & $\begin{array}{l}\text { To repair damaged } \\
\text { buildings; To repair or } \\
\text { replace poor-quality } \\
\text { components; To improve } \\
\text { building functions. }\end{array}$ & \\
\hline $\begin{array}{l}\text { Demolition of } \\
\text { Buildings }\end{array}$ & $\begin{array}{l}\text { Dangerous houses, vacant houses, } \\
\text { buildings or structures that affect } \\
\text { fire protection, and other buildings } \\
\text { that cannot be improved through } \\
\text { remediation. }\end{array}$ & $\begin{array}{l}\text { Demolition of existing } \\
\text { buildings, re-use of land or } \\
\text { rebuilding to original site. }\end{array}$ & 902 \\
\hline
\end{tabular}

\subsubsection{Road improvement guidance.}

Comprehensively consider the socio-economic and village development needs, on the basis of protecting the context of the housing estate and improving the road traffic system in the area (as shown in Figure 4), we need to widen or improve the quality of the original roads, and implement rectification by classification (as shown in Table 7 ).

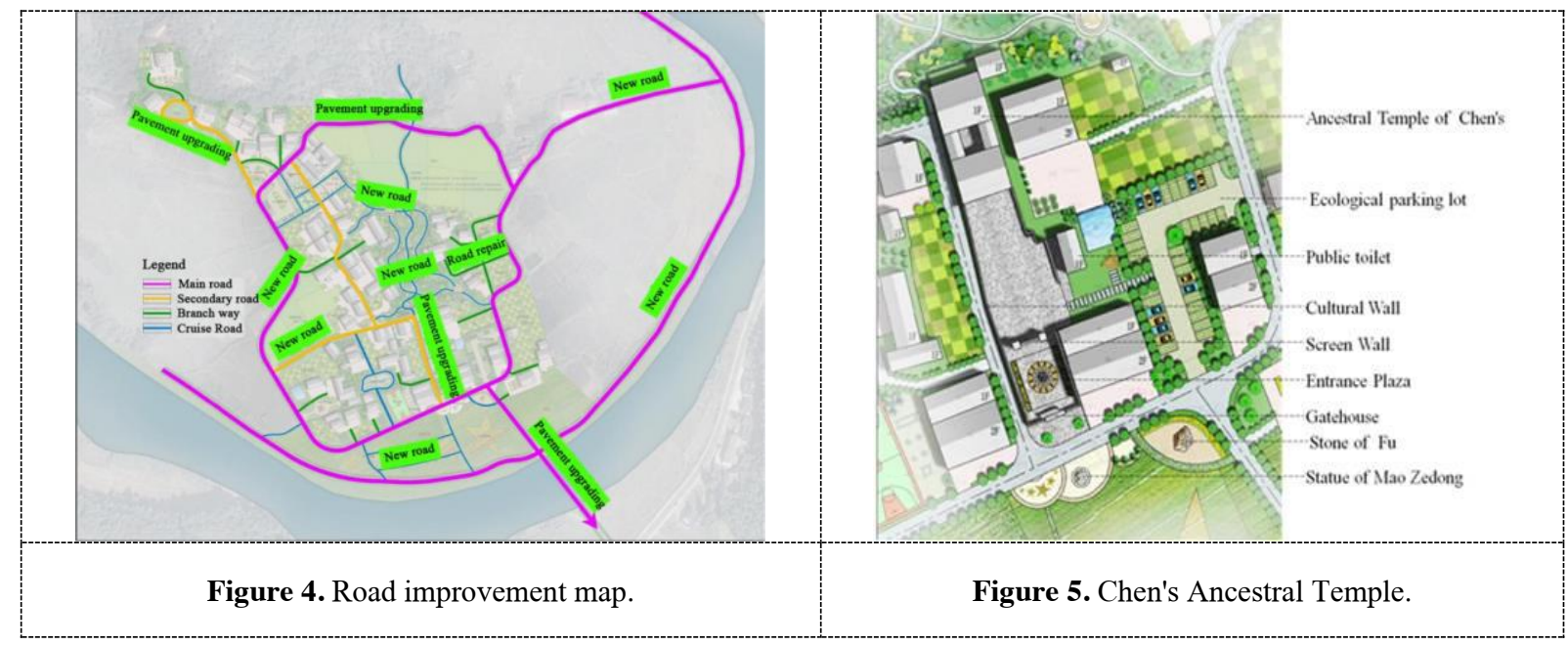


Table 7. Guidelines for road improvement.

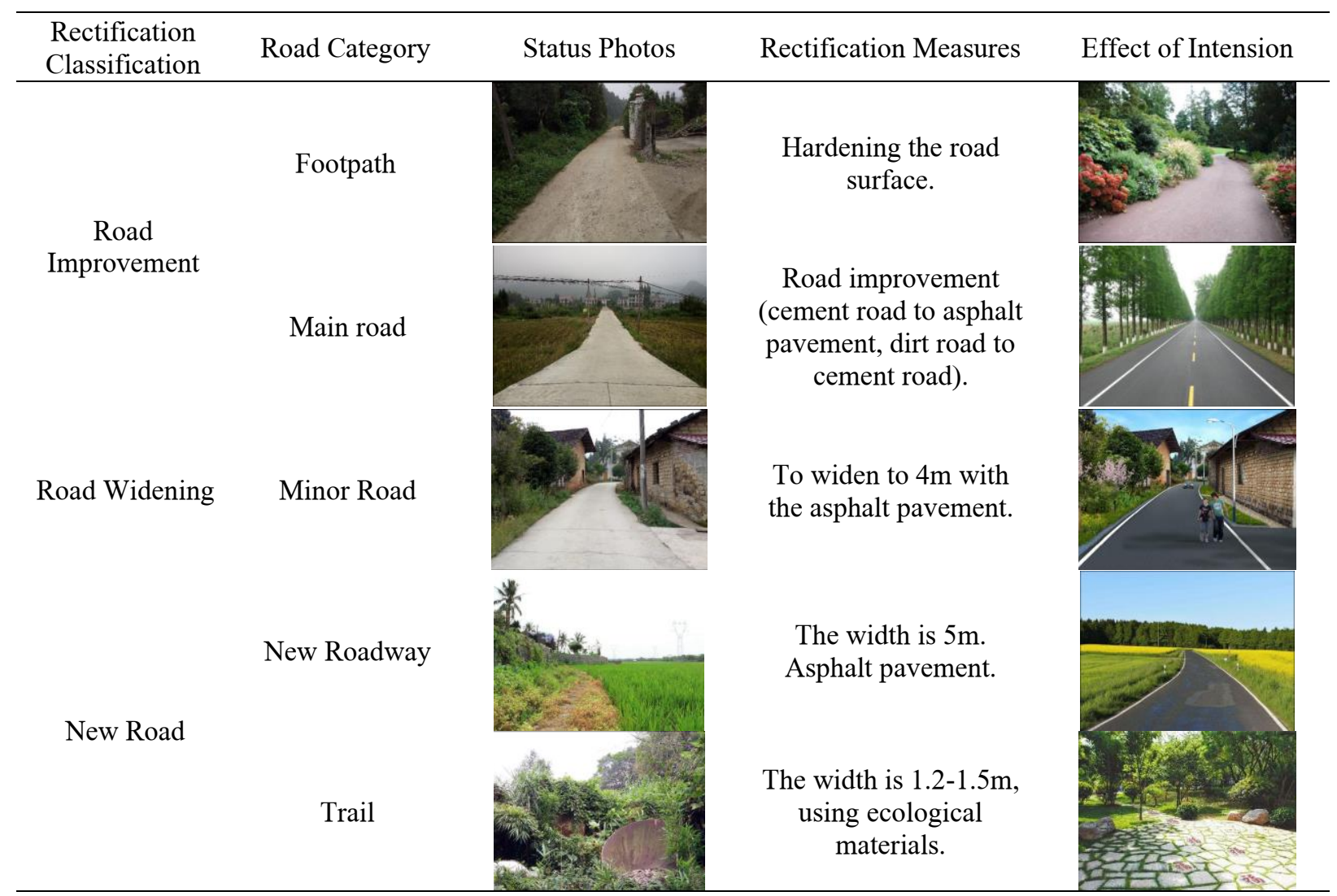

3.3.4. Nodes design. With the goal of demonstrating the culture of Hakka ancestral temple, inheriting the spirit of the Red Revolution, and serving the villagers of Qixi, the three node spaces with the Chen's Ancestral Temple, Chen Wuxing Ancestral Temple and Fu Garden as the core are formed.

\section{Chen's Ancestral Temple.}

Build a cultural exhibition space around the Chen's Ancestral Temple, which is suitable for both the villagers' production and life and tourists (as shown in Figure 5). Mainly elements such as ancestral temple, cultural wall, gate tower, Mao Zedong statue, and Fu stone, can create a cultural atmosphere. The entrance "stone" is engraved with the meaning of "blessing", which means that Mao Zedong turned the danger into safeness here and brought blessings to the visiting tourists; newly built gatehouse and screen wall, the words "Chen Ancestral Temple" were engraved on the gate and the publicity photos of the Chen family were attached to the screen wall; Reconstruct the current status of the cultural wall with the theme of "Hakka Ancestral Temple Culture + Red Culture". The white and gray tone will be used to make it coordinate with the ancestral temple. The discarded Qixi village committee will be demolished, and an ecological parking lot will be added. The Chen's Ancestral Temple will be maintained and repaired.

Chen Wuxing Temple.

Adopting the "dividing dynamic and static zone" design approach, the space surrounding Chen Wuxing Temple is built to integrate leisure and entertainment, fitness, recreation and cultural exhibition (as shown in Figure 6). The northeast side is the cultural exhibition and recreation space, and the southwest side is the space for sports and fitness and parking. The addition of cultural squares, fitness venues, ecological parking lots, and cleaning and repairing of the facade of the Chen Wuxing Ancestral Temple not only meets the needs of tourists for sightseeing, viewing, playing, and rest, but also meets the needs of tourists. 


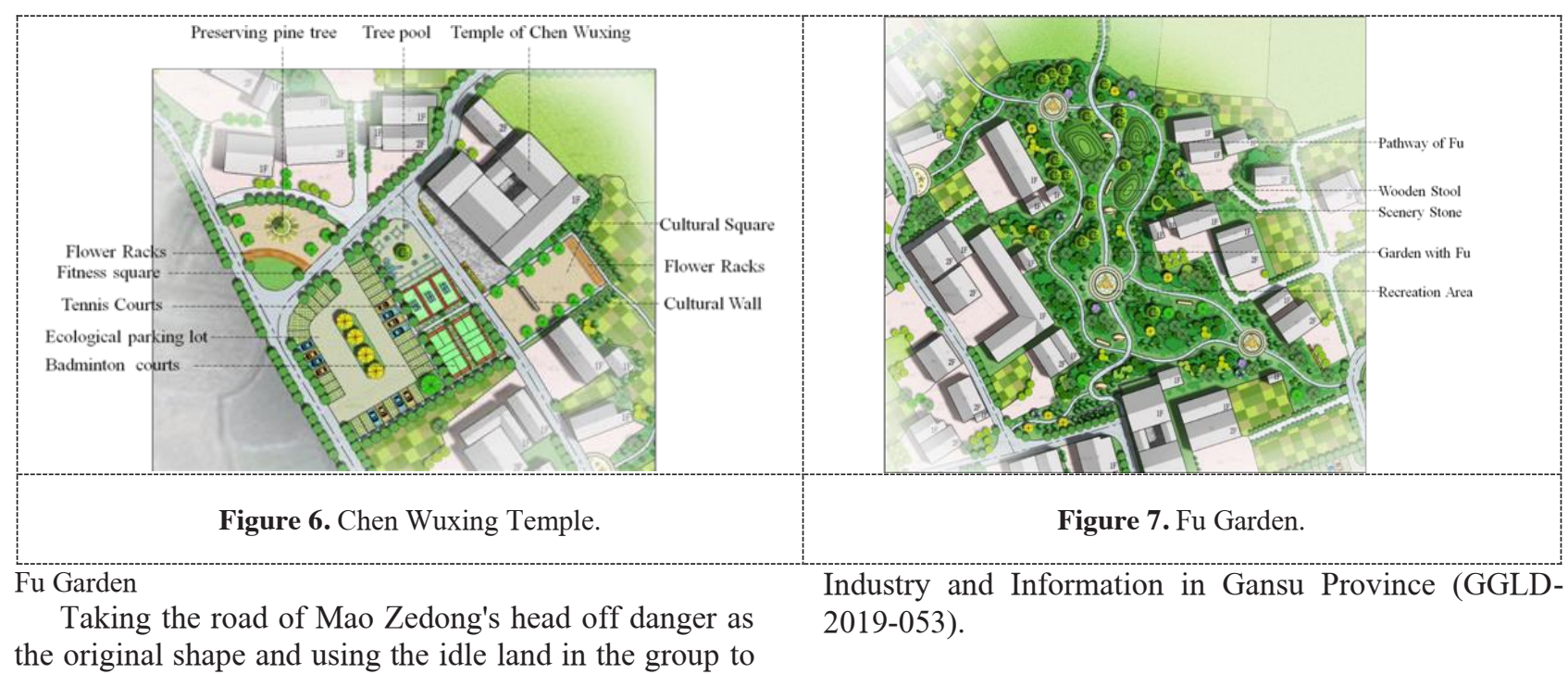
the park, with a simple white tone, and the ground is scattered with dark wood grain vitrified floor tiles with the character of "Fu" inlaid between the trails (as shown in Figure 7). A lounge area with wooden creative stools is enclosed by a blessing tree to form a private space. A "Fu" stone and wooden stools are set up along the walkway for tourists to rest.

\section{Conclusion}

Based on theoretical research and practical cases, this paper explores the methods and measures for the renovation of beautiful villages in the context of global tourism, and elaborates the main contents of beautiful village renovation from the four aspects of overall functional layout, building shape renovation, environmental appearance renovation, and infrastructure support. The construction of a beautiful village under the background of global tourism is a systemic project with a long and arduous task, which cannot be accomplished overnight. The renovation and construction of buildings, roads, and landscape nodes in the renovation of beautiful villages need to be assisted by numerous guarantee mechanisms to determine the content and depth in combination with the actual conditions and development laws of the villages, and implement them step by step [5]. The renovation of beautiful villages can promote the better development of tourism in the whole region, and the global tourism also provides a certain theoretical guidance for the renovation of beautiful villages. It is hoped that the research in this paper can provide certain references and ideas for the renovation of similar villages.

\section{Acknowledgments}

This work was supported by the Second batch of the industry-academia collaborative education project of the Ministry of Education in 2018(201802142005), "Thirteenth Five-Year Plan" education science plan in Gansu Province (GS [2018] GHBBK030), and 2018 Education and Teaching Research Project in Longdong University (2018-16), 2019 Project of the Ministry of

\section{References}

1. Xu H., Chang G.S. (2017) On the Comprehensive Tourism Development from 3-Dimensions Perspectives: Concept Refining and Practical Extension. Journal of Kaili University, 04:34-39.

2. Zhu D.G., Jiang X.Y. (2018) Evaluation of Industry Integration of Shaoshan Red Tourism from the Perspective of Comprehensive Tourism. Journal of Hunan Finance and Economics University, 01:53-61.

3. Guo L. (2009) Out of Zuyin-A Study of the Village Management Model in Gannan. Shandong People Press, Jinan.

4. Zeng F. (2013) The preliminary study in village landscape planning based on urban design practices. Wuhan University of Technology, Wuhan.

5. Deng S.L., Shi J. (2015) Preliminary Study on Village Renovation from Beautiful Village Perspective: the Case of Anlezhuang Village, Koudong Town, Baodi District, Tianjin. Journal of Tianjin Chengjian University, 03:157-162. 